\title{
Oral Examination
}

\section{J. M. Hendry, MD', and Douglas R. McKay, MD, MBA, FRCSC'}

\section{Case I}

\section{Radial Wrist Pain}

A 65-year-old male presents to clinic complaining of base of thumb pain. He believes this is related to a previous fall on outstretched hand.

Objective 1: The candidate can appropriately interpret radiographs.

Question 1: Interpret the following radiographs and describe what you see to support your diagnosis

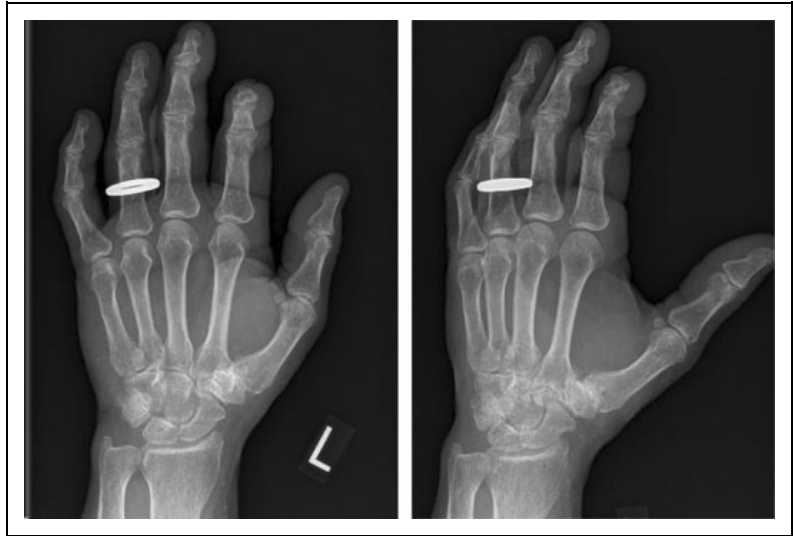

First CMC osteoarthritis

- sclerosis

- osteophytes

- subchondral cysts

- base of thumb subluxation

Objective 2: The candidate can classify first CMC osteoarthritis.

Questions 2: Classify first CMC osteoarthritis

Eaton-Littler classification for First CMC arthritis

\section{Stage Descriptions}

I Subtle carpometacarpal joint space widening

II Slight carpometacarpal joint space narrowing, sclerosis, and cystic changes with osteophytes or loose bodies $<2 \mathrm{~mm}$

III Advanced carpometacarpal joint space narrowing, sclerosis, and cystic changes with osteophytes or loose bodies $>2 \mathrm{~mm}$

IV Arthritic changes in the carpometacarpal joint as in stage III with scaphotrapezial arthritis

\footnotetext{
Objective 3: The candidate can describe the management of first CMC osteoarthritis.

Question 3: What are the treatment options for this patient.

- NSAIDS, physiotherapy

- Steroid injection

- Ultrasound guided steroid injection

- Joint replacement

\section{Case 2}

\section{Vascular Malformation of the Hand}

A 47-year-old man presents with a longstanding lesion on the left hand. It had recently become painful. There is a palpable soft tissue lesion on the left long finger.

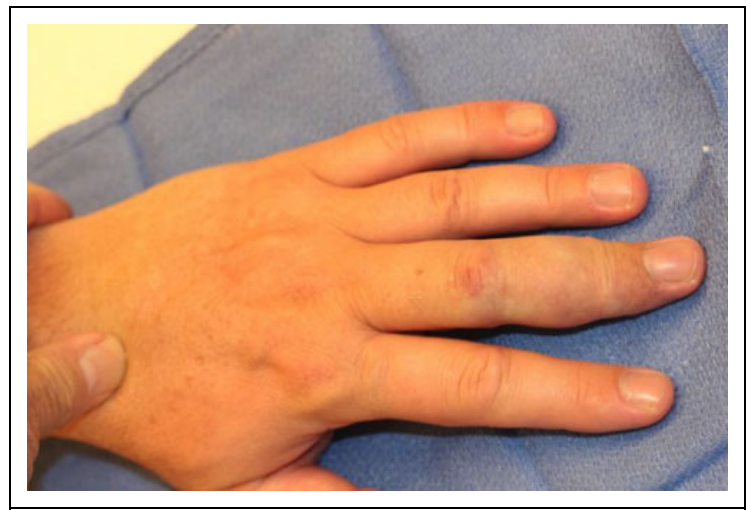

Objective 1: The candidate can develop a differential diagnosis for soft tissue lesions of the hand.

Question 1: What is your differential for a soft tissue lesion of the hand.

@SAGE
} OI: 10.1 I 77/22925503/8807925 journals.sagepub.com/home/psg 


\begin{tabular}{ll}
\hline Benign & Malignant \\
\hline Epidermal inclusion cyst & Primary: \\
Ganglion & Cutaneous malignancy \\
Giant cell tumor of the hand & Sarcoma \\
Dupuytren's disease & Secondary: \\
Vascular lesion & Metastatic deposit \\
Nerve sheath tumor & \\
Bone tumor (Enchodroma) & \\
Infection/abscess & \\
\hline
\end{tabular}

Objective 2: The candidate orders appropriate imaging to make the diagnosis.

Question 2: The lesion is pulsatile on palpation. What imaging would you order first to better characterize this lesion?

- Ultrasound

- \pm MRI

Objective 3: The candidate can order the appropriate imaging to determine if the lesion is amenable to surgical resection.

Question 3: The ultrasound confirms the presence of an AVM. The patient would like it resected. What test would you order prior to operating?
- Angiogram

- MR angiogram

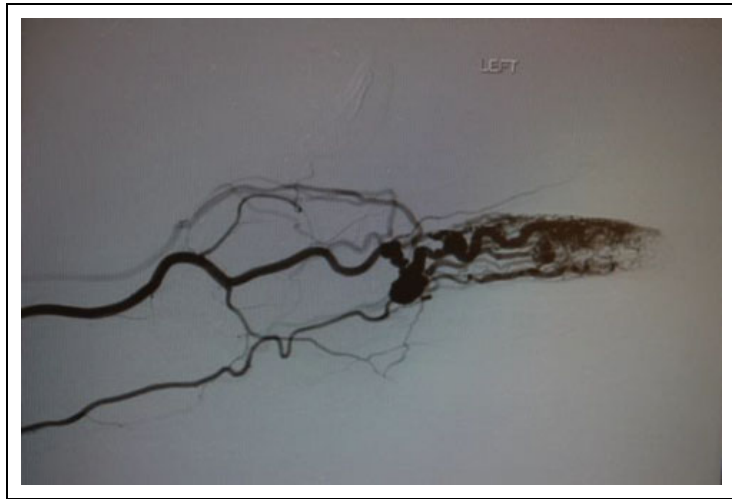

Objective 4: The candidate can outline a surgical plan for resection.

Question 4: What procedure would you obtain consent to perform?

- Resection of AVM finger

- \pm microsurgical reconstruction

- \pm vein grafts (volar wrist, dorsal foot)

- \pm amputation. 